\title{
Biomechanical study of injectable hollow pedicle screws for PMMA augmentation in severely osteoporotic lumbar vertebrae: effect of PMMA distribution and volume on screw stability
}

\author{
*Da Liu, MD, PhD, ${ }^{1}$ Jun Sheng, MD, PhD, ${ }^{1}$ Hong-hua Wu, MB, ${ }^{1}$ Xia Kang, MM, ${ }^{1}$ \\ Qing-yun Xie, MD, PhD, ${ }^{1}$ Yang Luo, MB, ${ }^{2}$ Jiang-jun Zhou, MD, PhD, ${ }^{3}$ and Wei Zheng, MD, PhD' \\ Departments of ${ }^{1}$ Orthopaedics and ${ }^{2}$ Anesthesiology, Chengdu Military General Hospital, Chengdu, Sichuan Province; and \\ 32Department of Orthopaedics, 184 Hospital of Nanjing Military Region, Yingtan, Jiangxi Province, People's Republic of China
}

\begin{abstract}
OBJECTIVE The purpose of this study was to compare stability of injectable hollow pedicle screws with different numbers of holes using different volumes of polymethylmethacrylate (PMMA) in severely osteoporotic lumbar vertebrae and analyze the relationship between screw stability and distribution and volume of PMMA.
\end{abstract}

METHODS Forty-eight severely osteoporotic cadaveric lumbar vertebrae were randomly divided into 3 groups-groups $A, B$, and $C$ (16 vertebrae per group). The screws used in group $A$ had 4 holes (2 pairs of holes, with the second hole of each pair placed $180^{\circ}$ further along the thread than the first). The screws used in group B had 6 holes ( 3 pairs of holes, placed with the same $180^{\circ}$ difference in position). Unmodified conventional screws were used in group $\mathrm{C}$. Each group was randomly divided into subgroups $0,1,2$, and 3 , with different volumes of PMMA used in each subgroup. Type A and $B$ pedicle screws were directly inserted into the vertebrae in groups $A$ and $B$, respectively, and then different volumes of PMMA were injected through the screws into the vertebrae in subgroups $0,1,2$, and 3 . The pilot hole was filled with different volumes of PMMA followed by insertion of screws in groups C0, C1, C2, and C3. Distributions of PMMA were evaluated radiographically, and axial pull-out tests were performed to measure the maximum axial pullout strength $\left(F_{\text {max }}\right)$. RESULTS Radiographic examination revealed that PMMA surrounded the anterior third of the screws in the vertebral bodies (VBs) in groups $A 1, A 2$, and $A 3$; the middle third of screws in the junction area of the vertebral body (VB) and pedicle in groups B1, B2, and B3; and the full length of screws evenly in both VB and pedicle in groups C1, C2, and C3. In addition, in groups $A 3$ and $B 3, P M M A$ from each of the screws (left and right) was in contact with PMMA from the other screw and the PMMA was closer to the posterior wall and pedicle than in groups $A 1, A 2$, B1, and B2. One instance of PMMA leakage was found (in group B3). Two-way analysis of variance revealed that 2 factors-distribution and volume of PMMA — significantly influenced $F_{\max }(p<0.05)$ but that they were not significantly correlated $(p=0.078)$. The $F_{\max }$ values in groups in which screws were augmented with PMMA were significantly better than those in groups in which no PMMA was used $(p<0.05)$.

CONCLUSIONS PMMA can significantly improve stability of different injectable pedicle screws in severely osteoporotic lumbar vertebrae, and screw stability is significantly correlated with distribution and volume of PMMA. The closer the PMMA is to the pedicle and the greater the quantity of injected PMMA used, the greater the pedicle screw stability is. Injection of $3.0 \mathrm{~mL}$ PMMA through screws with 4 holes (2 pair of holes, with the screws in each pair placed on opposite sides of the screw) produces optimal stability in severely osteoporotic lumbar vertebrae.

https://thejns.org/doi/abs/10.3171/2018.4.SPINE171225

KEYWORDS severe osteoporosis; injectable hollow pedicle screw; polymethylmethacrylate volume; polymethylmethacrylate distribution; maximum axial pullout strength; lumbar vertebrae

ABBREVIATIONS BMD = bone mineral density; $F_{\max }=$ maximum axial pullout strength; $P M M A=$ polymethylmethacrylate; $V B=$ vertebral body SUBMITTED November 15, 2017. ACCEPTED April 18, 2018.

INCLUDE WHEN CITING Published online September 7, 2018; DOI: 10.3171/2018.4.SPINE171225.

* D.L., J.S., and H.H.W. contributed equally to this study and share first authorship. 
$\mathrm{D}$ UE to its high fixation strength, the pedicle screw technique has been widely performed in posterior spinal surgery. ${ }^{15,16,17,25}$ However, osteoporosis severely destroys the bone microstructure and decreases the fixation strength of the screws, which usually leads to the serious complications of screw loosening and migration. ${ }^{10,23}$

Many researchers have used polymethylmethacrylate (PMMA) to improve pedicle screw fixation strength in

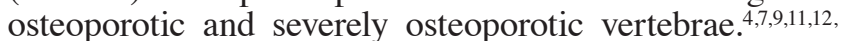
${ }^{19,20}$ Also, hollow injectable pedicle screws with holes have been designed and PMMA has been injected through these screws into the surrounding bone to enhance fixation. ${ }^{1-3,5,6,8,13,21,22,24}$ There are obvious differences among these studies with respect to the injectable screws and their use, including placement of holes, volumes of injected PMMA, and screw stability. However, there have been neither biomechanical comparisons of screw stability for different injectable screws and different PMMA volumes nor any research on the relationship between screw fixation strength and distribution and volume of PMMA used specifically in severely osteoporotic lumbar vertebrae.

In a previous study, Liu et al. compared screw stability with several different volumes of PMMA in traditional augmentation of full-length screws in severely osteoporotic lumbar vertebrae. ${ }^{19}$ The study showed a significant positive correlation between screw stability and volume of PMMA, and the authors suggested that $3.0 \mathrm{~mL}$ is the optimal volume of PMMA. That study was focused on only the relationship between PMMA volume and screw fixation strength, while no studies have focused on the relationship between PMMA distribution and screw fixation strength.

Thus, in this study we planned to inject different volumes of PMMA through injectable hollow pedicle screws with different holes into severely osteoporotic lumbar vertebrae to compare screw fixation strength of pedicle screws with different numbers of holes augmented with different volumes of PMMA; to analyze the relationship between screw fixation strength, distribution pattern, and injected volume of PMMA; and to conduct a preliminary analysis of the optimal injectable screw design and optimal volume of PMMA for lumbar vertebrae with severe osteoporosis.

\section{Methods \\ Ethics Statement}

All procedures involving human cadaveric specimens were conducted according to the ethics guidelines established by our local ethics committee. The approval for our protocol was obtained from the ethics committee of Chengdu Military General Hospital.

\section{Specimen Preparation}

Radiographic examinations were performed on all samples to exclude specimens with fractures, deformity, and osteolysis resulting from malignancy. A total of 48 lumbar vertebrae (L1-L5) were obtained from 10 freshfrozen spines from cadavers ( 8 women and 2 men) with a mean age of 66 years (range 58-73 years). Dual-energy
X-ray absorptiometry (Lunar Corp.) measurements were performed on all spines, and the definition of severe osteoporosis from the World Health Organization was used to assess all vertebrae. Single vertebrae were completely removed from the spine and stored at $-20^{\circ} \mathrm{C}$ for further use.

\section{Pedicle Screws and Placement}

The pedicle screws used in this study were conventional pedicle screws made of titanium alloy. They were 45 $\mathrm{mm}$ long, had a diameter of $6.5 \mathrm{~mm}$, a thread height of 1 $\mathrm{mm}$, and a pitch of $2.75 \mathrm{~mm}$ (Medtronic Weigao Orthopedic Device Co., Ltd.). For groups A and B, the screws were modified to make them injectable.

Group A consisted of injectable screws with 4 holes (Fig. 1A). The first hole (hole 1) was placed at a distance of $5 \mathrm{~mm}$ from the screw tip, and the second hole (hole 2) was placed at a point identified by rotating $180^{\circ}$ along the thread from the first hole, so that holes 1 and 2 were on opposite sides of the pedicle screw. The third hole (hole 3) was positioned directly above the first hole, 1 thread apart. The fourth hole (hole 4 ) was placed at a point $180^{\circ}$ along the thread from hole 3, directly above and separated by 1 thread from hole 2. Group B consisted of injectable screws with 6 holes (Fig. 1B). Holes 1-4 were placed as for group A. The fifth hole (hole 5) was placed directly above holes 1 and 3 (in a straight line), 1 thread above hole 3 . The sixth hole (hole 6) was placed at a point $180^{\circ}$ along the thread from hole 5. Conventional pedicle screws, without holes, were used in group C (Fig. 1C). PMMA (Cemex, Tecres), including cement powder and cement solution, was used for screw augmentation.

\section{Experimental Procedures}

The 48 osteoporotic vertebrae were randomly divided into groups A, B, and C (16 vertebrae per group), and then the groups were randomly divided into subgroups $0,1,2$, and 3, with different volumes of PMMA used in each subgroup (4 vertebrae, with 8 pedicles, in each subgroup). The pilot hole was made along the axis of the pedicle with the same method used in the previous study by Liu et al. ${ }^{19}$ The hole was checked with a probe to verify pedicle integrity.

Type A and type B screws were directly inserted into vertebrae in groups A and B, respectively, and then different volumes of PMMA were injected through the screws into the vertebrae in subgroups $0(0 \mathrm{~mL}), 1(2.0 \mathrm{~mL}), 2(2.5$ $\mathrm{mL})$, and $3(3.0 \mathrm{~mL})$, respectively. In group C, the pilot holes were injected with different volumes of PMMA (0 in subgroup $\mathrm{C} 0,2.0$ in $\mathrm{C} 1,2.5$ in $\mathrm{C} 2$, and $3.0 \mathrm{~mL}$ in $\mathrm{C} 3$ ), and then the conventional pedicle screws were inserted. All specimens were kept moist with resin at room temperature throughout this procedure. Twenty-four hours after injection of PMMA, radiographic examination was performed on all samples to determine screw position and PMMA distribution.

\section{Axial Pullout Tests}

Axial pullout tests were performed through the MTS 858 Material Testing System (MTS Systems) after radiographic examination. The samples were mounted onto a special jig to ensure that each screw was pulled strictly 


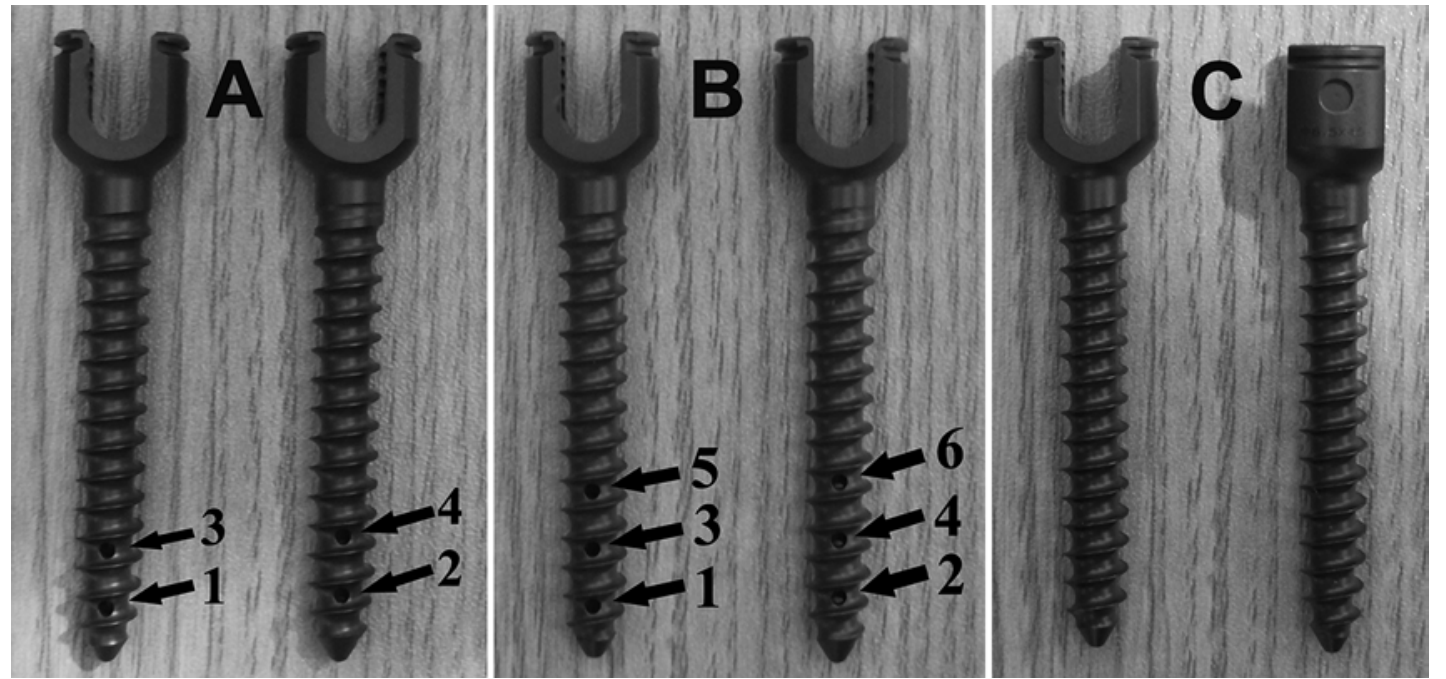

FIG. 1. The 3 different kinds of pedicle screws used in this study. $A, B$, and $C$ show, respectively, the injectable pedicle screw with 4 holes (used for group A), the injectable pedicle screw with 6 holes (used for group B), and the conventional pedicle screw with no holes (used for group C). In each image, the left side of the screw is shown on the left and the right side of the screw on the right. The holes were numbered as shown, with holes 1,3 , and 5 being on the left side of the screw and holes 2, 4, and 6 being on the right side. For a complete description of hole placement, please refer to Pedicle Screws and Placement in Methods.

along its long axis. Each screw was pulled at a constant speed of $5 \mathrm{~mm} /$ minute until screw failure. The load and displacement data collected in real time at $50 \mathrm{~Hz}$ were used to obtain the load-displacement curve. On the curve, the maximum pullout strength $\left(\mathrm{F}_{\max }\right)$ was defined as the highest point that was also the inflection point between the ascending and descending parts of the curve.

\section{Statistical Analysis}

Statistical analysis was performed using SPSS software (version 16.0; SPSS Inc.). The data are expressed as mean \pm standard deviation. One-way analysis of variance was used to detect differences in bone mineral density (BMD) among all groups. Two-way analysis of variance was used to detect the relationship between distribution and volume of PMMA and $\mathrm{F}_{\max }$ and the Bonferroni correction was used to detect significant difference in $\mathrm{F}_{\max }$ between any 2 groups. A p value $<0.05$ was considered statistically significance.

\section{Results}

\section{Bone Mineral Density of the Vertebrae}

All $\mathrm{T}$ values were lower than -3.5 , and there was no statistically significant difference in BMD among the 12 groups (A0 through $\mathrm{C} 3$ ). All vertebrae used in this study were determined to be severely osteoporotic.

\section{Radiographic Examination}

PMMA distribution and screw position were clearly shown on radiographs (Figs. 2-4). In groups A0, B0, and $\mathrm{C} 0$, there was no PMMA around the screws. PMMA was evident surrounding the anterior third of the screw in the vertebral body (VB) in groups A1-A3, surrounding the middle third of the junction area of the VB and pedicle in groups B1-B3, and surrounding the full length of the screw evenly in both the VB and the vertebral pedicle in groups $\mathrm{C} 1-\mathrm{C} 3$. In addition, in groups A3 and B3, PMMA from the screws in one side of the specimen was contact-
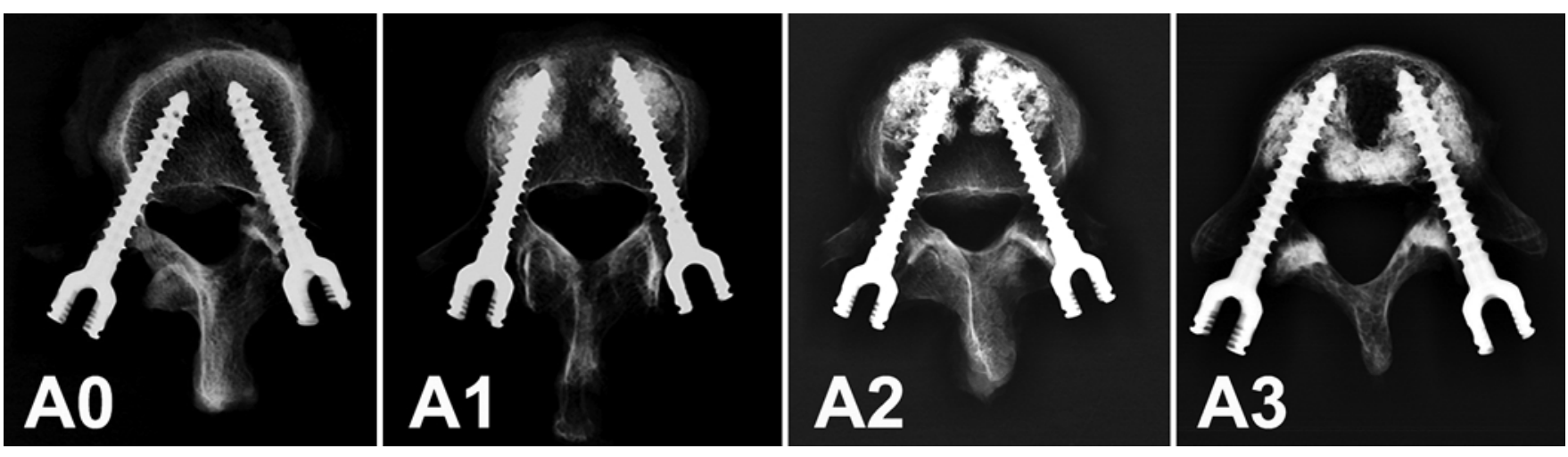

FIG. 2. Radiographs of PMMA distribution in groups $A 0, A 1, A 2$, and $A 3$. 

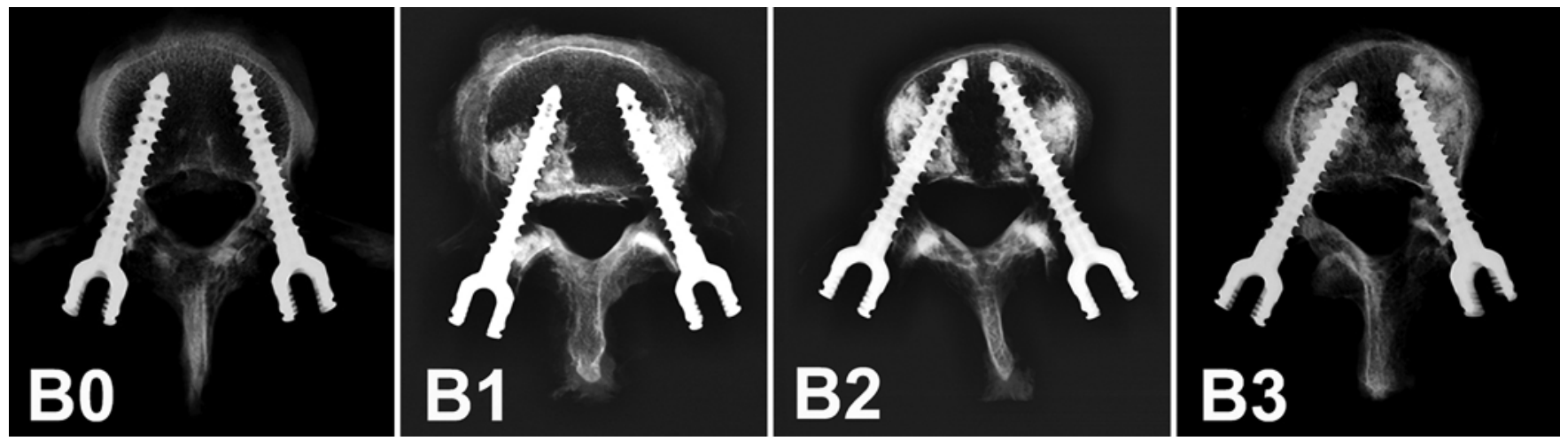

FIG. 3. Radiographs of PMMA distribution in groups $\mathrm{B} 0, \mathrm{~B} 1, \mathrm{~B} 2$, and $\mathrm{B} 3$.

ing PMMA from the other screw placed in the specimen and the PMMA was closer to the posterior wall and pedicle of vertebra than in groups A1, A2, B1, and B2. In groups A1 through A3, groups B1 through B3, and groups $\mathrm{C} 1$ through $\mathrm{C} 3$, there was a gradually broadening scope of PMMA distribution around the screws. No screw malposition was seen in any of the specimens. One instance of PMMA leakage was found (in a group B3 specimen).

\section{Axial Pullout Tests}

As shown in Table 1,2-way analysis of variance revealed that 2 factors - distribution and volume of PMMA-had a significant influence on $\mathrm{F}_{\max }(\mathrm{p}<0.05)$, and there was no significant correlation between the distribution of PMMA and volume of PMMA ( $\mathrm{p}=0.078)$.

The $\mathrm{F}_{\max }$ in groups $\mathrm{A} 1, \mathrm{~A} 2$, and $\mathrm{A} 3$ was increased by $59.9 \%, 100.6 \%$, and $178.3 \%$, respectively, in comparison with the $\mathrm{F}_{\max }$ in group A0. There was no statistically significant difference in $F_{\text {max }}$ between groups $A 1$ and $A 2$ (p $=0.552$ ), and the $F_{\max }$ in group A3 was significantly higher than that in groups A1 and A2 ( $<<0.05)$. The $F_{\max }$ in groups B1, B2, and B3 was increased by $106.4 \%, 149.7 \%$, and $209.2 \%$, respectively, in comparison with that in group B0. There was no statistically significant difference in $\mathrm{F}_{\max }$ between groups $\mathrm{B} 1$ and $\mathrm{B} 2(\mathrm{p}=0.209)$, and the $\mathrm{F}_{\max }$ in group B3 was significantly higher than that in groups $\mathrm{B} 1$ and $\mathrm{B} 2(\mathrm{p}<0.05, \mathrm{p}=0.004)$. The $\mathrm{F}_{\max }$ in groups $\mathrm{C} 1$,
C2 and C3 was increased by $105.2 \%, 147.0 \%$, and $201.0 \%$, respectively, in comparison with that of group $\mathrm{C} 0$. There was no statistically significant difference in $\mathrm{F}_{\max }$ between groups $\mathrm{C} 1$ and $\mathrm{C} 2(\mathrm{p}=0.328)$, and the $\mathrm{F}_{\max }$ in group $\mathrm{C} 3$ was significantly higher than that in groups $\mathrm{C} 1$ and $\mathrm{C} 2 \mathrm{p}$ $<0.05, \mathrm{p}=0.023$ ).

There were no statistically significant differences between groups $\mathrm{A} 0, \mathrm{~B} 0$, and $\mathrm{C} 0(\mathrm{p}>0.05)$ or between groups $A 3, B 3$, and $C 3(p>0.05)$. The $F_{\text {max }}$ in group A1 was significantly lower than that in groups $\mathrm{B} 1$ and $\mathrm{C} 1(\mathrm{p}=0.008$, $\mathrm{p}=0.043$ ), and the $\mathrm{F}_{\max }$ in group A2 was significantly lower than that in groups B2 and $\mathrm{C} 2(\mathrm{p}=0.002, \mathrm{p}=0.023)$. There were no statistically significant differences between groups $\mathrm{B} 1$ and $\mathrm{C} 1(\mathrm{p}=1.000)$ or between groups $\mathrm{B} 2$ and $\mathrm{C} 2(\mathrm{p}=1.000)$.

The $\mathrm{F}_{\max }$ in group $\mathrm{A} 0$ was markedly lower than that in groups $\mathrm{B} 1, \mathrm{~B} 2, \mathrm{~B} 3, \mathrm{C} 1, \mathrm{C} 2$, and $\mathrm{C} 3(\mathrm{p}<0.05)$. The $\mathrm{F}_{\max }$ in group A1 was markedly higher than that in groups $\mathrm{B} 0$ and $\mathrm{C} 0(\mathrm{p}=0.047, \mathrm{p}=0.024)$ and significantly lower than that in groups B2, B3, C2, and C3 $(\mathrm{p}<0.05)$. The $\mathrm{F}_{\max }$ in group A2 was significantly higher than that in groups B0 and C0 ( $p<0.05)$ and significantly lower than that in groups B3 and C3 $(\mathrm{p}<0.05)$ but not significantly different from that in group $\mathrm{B} 1$ or $\mathrm{C} 1(\mathrm{p}>0.05)$. The $\mathrm{F}_{\max }$ in group A3 was significantly higher than that in groups B0, $\mathrm{B} 1, \mathrm{C} 0$, and $\mathrm{C} 1(\mathrm{p}<0.05, \mathrm{p}=0.017, \mathrm{p}<0.05, \mathrm{p}=0.003)$ but not significantly different from that in group B2 or $\mathrm{C} 2$ ( $p>0.05)$. The $\mathrm{F}_{\max }$ in group B0 was markedly lower
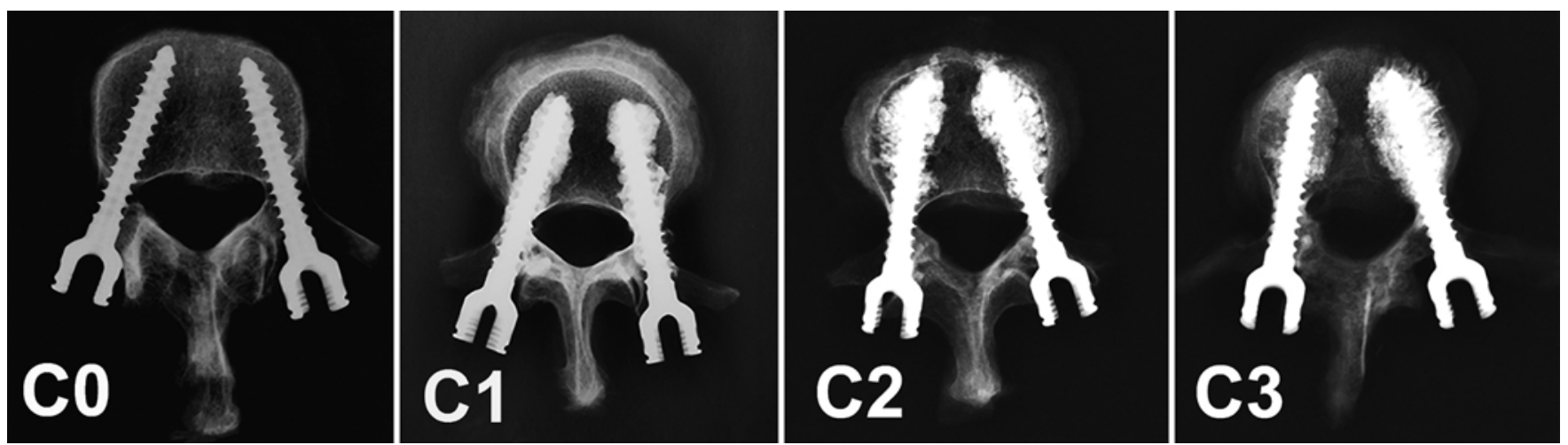

FIG. 4. Radiographs of PMMA distribution in groups $\mathrm{C} 0, \mathrm{C} 1, \mathrm{C} 2$, and $\mathrm{C} 3$. 
TABLE 1. Maximum pullout strength $\left(F_{\max }\right)$ for screws in all groups

\begin{tabular}{ccccc}
\hline & \multicolumn{4}{c}{ Vol of PMMA $(\mathrm{mL})$} \\
\cline { 2 - 4 } Screw Group & $0(0 \mathrm{~mL})$ & $1(2.0 \mathrm{~mL})$ & $2(2.5 \mathrm{~mL})$ & $3(3.0 \mathrm{~mL})$ \\
\hline A & $356.0 \pm 79.8$ & $569.3 \pm 89.8^{*}$ & $714.1 \pm 103.5^{*}$ & $990.8 \pm 125.8 \dagger$ \\
\hline B & $380.8 \pm 82.8$ & $786.0 \pm 107.8$ & $949.0 \pm 116.2$ & $1177.5 \pm 145.6 \dagger$ \\
\hline C & $370.0 \pm 75.2$ & $759.1 \pm 105.4$ & $913.9 \pm 97.7$ & $1113.8 \pm 133.0 \dagger$ \\
\hline
\end{tabular}

Data are shown as mean \pm SD of 16 vertebrae (32 pedicle screws) per group (4 vertebrae and 8 pedicle screws per PMMA-volume subgroup). $\dagger$ Statistically significant difference $(p<0.05)$ for comparison with PMMA-volume subgroups 1 and 2 in the same screw group.

* Statistically significant difference $(p<0.05)$ for comparison with $B$ and $C$ at the same PMMA volume.

than that in groups $\mathrm{C} 1, \mathrm{C} 2$, and $\mathrm{C} 3(\mathrm{p}<0.05)$. The $\mathrm{F}_{\max }$ in group $\mathrm{B} 1$ was significantly higher than that in group $\mathrm{C} 0$ $(\mathrm{p}<0.05)$, significantly lower than that in group C3 ( $\mathrm{p}<$ $0.05)$, and not significantly different from that in group $\mathrm{C} 2$ $(\mathrm{p}=0.000)$. The $\mathrm{F}_{\max }$ in group $\mathrm{B} 2$ was markedly higher than that in groups $\mathrm{C} 0$ and $\mathrm{C} 1(\mathrm{p}<0.05, \mathrm{p}=0.043)$ but not significantly different from that in group C3 $(p=0.190)$. The $\mathrm{F}_{\max }$ in group $\mathrm{B} 3$ was significantly higher than that in groups $\mathrm{C} 0, \mathrm{C} 1$, and $\mathrm{C} 2(\mathrm{p}<0.05)$.

\section{Discussion}

Although directly injecting PMMA into the screw track in the traditional method can significantly enhance screw stability in the setting of osteoporosis, there is the potential risk of leakage of PMMA into the pedicle if the screw is completely enveloped in PMMA. It is becoming more common to design injectable pedicle screws that are hollow and have holes so that PMMA can be injected through the screws and into surrounding bone to augment fixation. Studies have shown that there are marked differences regarding screw stability among various injectable pedicle screws with holes and different volumes of injected PMMA (Table 2). Most importantly, there have been fewer studies of the relationship between pedicle screw fixation strength and PMMA distribution and PMMA volume used in severe osteoporosis. In this study, we designed injectable pedicle screws with different holes and injected different volumes of PMMA into them after placement in severely osteoporotic lumbar vertebrae. We analyzed the relationship between screw stability and PMMA distribution and PMMA volume through radiographic examination and biomechanical testing to determine the optimal injectable screw configuration and PMMA volume for lumbar vertebrae with severe osteoporosis.

In a study reported in 2016, Liu et al. injected different volumes of PMMA using the traditional method of augmenting the full length of screws inserted in lumbar vertebrae with severe osteoporosis. ${ }^{19}$ This study showed that PMMA could significantly enhance screw stability and that there was a significant positive correlation between screw fixation strength and PMMA volume, but it also showed that increasing the volume of PMMA after a certain point did not significantly improve screw stability. The results suggested that $3.0 \mathrm{~mL}$ was the optimal volume of PMMA for screw fixation strength in lumbar vertebrae with severe osteoporosis. That study compared screw stability for different volumes of PMMA but not stability with different distributions of PMMA.
We designed injectable pedicle screws with different holes and compared screw stability augmented with different volumes of PMMA in osteoporotic synthetic bone in a preliminary study (unpublished data). We found that regardless of how many holes were used, PMMA always flowed from the hole closest to the head of the screw. Thus, we designed 2 kinds of injectable screws with different numbers of holes in order to achieve different distributions of PMMA. In this study, we found that PMMA wrapped around the anterior third of the screw in the VB in group $\mathrm{A}$, around the middle third of screw in the area of the junction of the VB and pedicle in group B, and around the full length of screws evenly in both the VB and the pedicle in group C. In addition, PMMA from one side of the screw was in contact with PMMA from the other side in groups $\mathrm{A} 3$ and B3 and the PMMA was closer to the posterior wall of the VB and pedicle in those two groups than in groups $\mathrm{A} 1, \mathrm{~A} 2, \mathrm{~B} 1$, and B2. But the main distribution of PMMA in groups $\mathrm{A} 3$ and $\mathrm{B} 3$ was also wrapping around the anterior third and middle third of the screw, respectively. Radiographic examination showed that, as we expected, there were different distributions of PMMA for each different type of screw. In the study by Liu et al., ${ }^{19}$ screw stability in severely osteoporotic lumbar vertebrae was significantly enhanced through injection of at least $2.0 \mathrm{~mL}$ PMMA, and 3.0 mL PMMA optimized screw stability, so we chose different volumes of PMMA (2.0, 2.5, and $3.0 \mathrm{~mL})$ for the current study.

In the present study, biomechanical tests showed that stability of screws placed with PMMA augmentation was significantly higher than that of screws placed without augmentation. We found the same distribution of PMMA in groups with the same injectable screw, and screw fixation strength increased with increasing PMMA volume. There was no statistically significant change in screw fixation strength when PMMA augmentation increased from $2.0 \mathrm{~mL}$ to $2.5 \mathrm{~mL}$ in groups $\mathrm{A}, \mathrm{B}$, and $\mathrm{C}$. However, there were significant increases in screw stability when PMMA augmentation increased from $2.0 \mathrm{~mL}$ to $3.0 \mathrm{~mL}$ and from $2.5 \mathrm{~mL}$ to $3.0 \mathrm{~mL}$, which supports the importance of the role of PMMA volume on the fixation strength of screw.

There was no statistically significant difference in screw stability among groups $\mathrm{A} 0, \mathrm{~B} 0$, and $\mathrm{C} 0$. With $2.0 \mathrm{~mL}$ and $2.5 \mathrm{~mL}$ of PMMA, screw stability in group A was significantly lower than in groups $\mathrm{B}$ and $\mathrm{C}$, and there was no significant difference between groups B and C. As we knew, there is cancellous bone in the VB and cortical bone in the pedicle, which may influence the augmentation effect of 
Liu et al.

TABLE 2. Volume of injected PMMA reported by various researchers

\begin{tabular}{|c|c|c|c|c|}
\hline $\begin{array}{l}\text { Authors } \\
\& \text { Year }\end{array}$ & Type of Study & Type of Injectable Screw & $\begin{array}{l}\text { Vol of Injected } \\
\text { PMMA (mL) }\end{array}$ & $\begin{array}{l}\text { Increase in Pedicle } \\
\text { Screw Stability }\end{array}$ \\
\hline $\begin{array}{l}\text { Fransen, } \\
2007\end{array}$ & $\begin{array}{l}\text { Clinical study in pts w/ osteo- } \\
\text { porosis \& severe osteoporo- } \\
\text { sis (T12-L1, L3-5) }\end{array}$ & $\begin{array}{l}\text { Cannulated screw w/ small holes on sides, allowing } \\
\text { PMMA injection into VB }\end{array}$ & 1.5 & \\
\hline $\begin{array}{l}\text { Becker et } \\
\text { al., } 2008\end{array}$ & $\begin{array}{l}\text { In vitro study in osteoporotic } \\
\text { lumbar vertebrae (L1-4) }\end{array}$ & $\begin{array}{l}\text { Perforated screw w/ central canal w/o distal opening \& } \\
2 \times 2 \text { holes at } 20 \% \& 40 \% \text { of thread length from tip }\end{array}$ & 2.0 & $79 \%$ \\
\hline $\begin{array}{l}\text { Blattert et } \\
\quad \text { al., } 2009\end{array}$ & $\begin{array}{l}\text { In vitro study in osteoporotic } \\
\text { thoracic \& lumbar vertebrae } \\
\text { (T9-L4) }\end{array}$ & $\begin{array}{l}\text { Cannulated-fenestrated pedicle screws }(6.5-\times 45- \\
\text { mm CD Horizon Legacy FNS fenestrated screw, } \\
\text { Medtronic) }\end{array}$ & 1.5 & \\
\hline $\begin{array}{l}\text { Chen et al., } \\
2009\end{array}$ & $\begin{array}{l}\text { In vitro study in severe osteo- } \\
\text { porotic synthetic bone block }\end{array}$ & $\begin{array}{l}\text { Group C0, central hole only; group C2, central hole } \\
\text { w/ } 2 \text { radial holes; group C4, central hole w/ } 4 \text { radial } \\
\text { holes; group C6, central hole w/ } 6 \text { radial holes; } \\
\text { group C8, central hole w/ } 8 \text { radial holes }\end{array}$ & 3 & \\
\hline $\begin{array}{l}\text { Waits et al., } \\
2009\end{array}$ & $\begin{array}{l}\text { In vitro study in osteopenic } \\
\text { lumbar vertebrae }\end{array}$ & $\begin{array}{l}\text { Novel cement-delivery screws fabricated from } 6.0-\times \\
45-\mathrm{mm} \text { cannulated Viper pedicle screws (DePuy } \\
\text { Spine, Inc.) w/ side fenestrations, } 2 \mathrm{~mm} \text { in diam, } \\
\text { milled btwn threads at tip of screw }\end{array}$ & 2.5 & \\
\hline $\begin{array}{l}\text { Moon et al., } \\
2009\end{array}$ & $\begin{array}{l}\text { Clinical study in pts w/ osteo- } \\
\text { porosis \& severe osteoporo- } \\
\text { sis (T2-S1) }\end{array}$ & $\begin{array}{l}\text { Screw w/ cannulation diam of either } 2.5 \mathrm{~mm}(6.5-\mathrm{mm} \\
\text { screw) or } 3.0 \mathrm{~mm} \text { ( } 7.5-\mathrm{mm} \text { screw) \& } 4 \text { holes, de- } \\
\text { signed so that one set of } 2 \text { holes is opposite other } \\
\text { set of } 2 \text { holes at distal end of screw }\end{array}$ & $1.7-2.0$ & \\
\hline $\begin{array}{l}\text { Bullmann et } \\
\text { al., } 2010\end{array}$ & $\begin{array}{l}\text { In vitro study in osteoporotic } \\
\text { thoracic \& lumbar vertebrae } \\
\text { (T7-L3) }\end{array}$ & $\begin{array}{l}\text { Screw w/ a conical core, a cylindrical outer diam w/ } \\
\text { cancellous-to-cortical threads, \& fenestrations in } \\
\text { ant part }\end{array}$ & $0.8-2.0$ & $28.7 \%$ \\
\hline $\begin{array}{l}\text { Paré et al., } \\
\quad 2011\end{array}$ & $\begin{array}{l}\text { In vitro study in osteoporotic } \\
\text { thoracic \& lumbar vertebrae } \\
\text { (T7-L5) }\end{array}$ & $\begin{array}{l}\text { Fenestrated screw: std multi-axial screw w/ } 6 \text { fenes- } \\
\text { trations in distal portion \& } 1 \text { opening at distal tip }\end{array}$ & $\begin{array}{l}\text { Thoracic vertebrae } \\
(0.5,1.0,1.5) \\
\text { \& lumbar } \\
\text { vertebrae }(1.5 \\
2.0,2.5)\end{array}$ & $\begin{array}{l}\text { Thoracic vertebrae, } 186 \% \\
\text { (1.0 mL) \& 158\% (1.5 } \\
\text { mL); lumbar vertebrae, } \\
264 \% \text { (1.5 mL), } 221 \% \\
(2.0 \mathrm{~mL}), \& 198 \% \text { ( } 2.5 \\
\mathrm{~mL})\end{array}$ \\
\hline $\begin{array}{l}\text { Choma et } \\
\text { al., } 2012\end{array}$ & $\begin{array}{l}\text { In vitro study in osteoporotic } \\
\text { thoracolumbar vertebrae } \\
\text { (T6-L5) }\end{array}$ & $\begin{array}{l}\text { Screw geometry varied by being solid-core ("solid"), } \\
\text { partially cannulated w/ multiple side fenestrations } \\
\text { over distal half of screw ("Pfen"), or fully cannulated } \\
\text { w/ multiple side fenestrations over distal third of } \\
\text { screw ("Ffen") }\end{array}$ & 2 & $\begin{array}{l}230.8 \% \text { for "solid" screw, } \\
334.9 \% \text { for "Pfen" } \\
\text { screw, } 285.6 \% \text { for } \\
\text { "Ffen" screw }\end{array}$ \\
\hline $\begin{array}{l}\text { Chao et al., } \\
2013\end{array}$ & $\begin{array}{l}\text { In vitro study in osteoporotic } \\
\text { thoracolumbar vertebrae } \\
\text { (T10-L5) \& severe osteopo- } \\
\text { rotic synthetic bone block }\end{array}$ & $\begin{array}{l}\text { Screws w/ a 2-mm-diam center hole over screw tip \& } \\
9 \text { side holes ( } 1 \mathrm{~mm} \text { diam) over distal third }\end{array}$ & 2 & $\begin{array}{l}1154.7 \% \text { for cement pre- } \\
\text { filled group \& } 301.5 \% \\
\text { for cement-injected } \\
\text { group }\end{array}$ \\
\hline
\end{tabular}

Ant = anterior; diam = diameter; pts = patients; std = standard .

PMMA at different places around the screw track. PMMA was found mainly augmenting the surrounding cancellous bone in the VB in group A, augmenting the cancellous bone close to the pedicle in group $\mathrm{B}$, and augmenting both the cancellous bone in the VB and the cortical bone in the pedicle in group C. PMMA was distributed in a spherelike shape around the hole in both group A and group B. The diameter of the sphere-like shapes in groups A and B was larger than in group $\mathrm{C}$, enhancing local resistance to pullout in groups A and B. Furthermore, although the volume of PMMA was the same in groups $\mathrm{A}$ and $\mathrm{B}$ (2.0 and $2.5 \mathrm{~mL}$ ), the distribution of PMMA in group $B$ was closer to the pedicle than in group $\mathrm{A}$, resulting in further significant improvement in resistance to pullout in group B com- pared with group A. Though the diameter of distribution of PMMA in group $\mathrm{C}$ was smaller than in groups $\mathrm{A}$ and $\mathrm{B}$, PMMA wrapped around the entire length of screws, augmenting both cancellous bone in the VB and cortical bone in the pedicle in group $\mathrm{C}$ and improving screw stability to a significantly higher extent than in group A; there was no significant difference compared with group B.

There was no significant difference among the 3 groups with the injection of $3.0 \mathrm{~mL}$ PMMA. With injection of 3.0 $\mathrm{mL}$, PMMA from both sides flowed closed to the posterior wall and the pedicle of vertebrae and the PMMA from one screw contacted that from the other. This change of PMMA distribution improved the screw stability in both group A3 and group B3, resulting in no significant differ- 
ence among groups A3, B3, and C3, which shows the influence on screw fixation strength of PMMA distribution. We confirmed via 2-way analysis of variance that distribution and volume of PMMA significantly influenced $\mathrm{F}_{\max }(\mathrm{p}$ $<0.05)$; there was no significant correlation between the distribution of PMMA and volume of PMMA $(p=0.078)$.

Comparative study revealed that the $\mathrm{F}_{\max }$ in group $\mathrm{A} 1$ was significantly lower than that in group B2, B3, C2, and $\mathrm{C} 3(\mathrm{p}<0.05)$. The $\mathrm{F}_{\max }$ in group A2 was significantly lower than that in groups B3 and C3 $(\mathrm{p}<0.05)$, but it was not significantly different from that in group B1 or group $\mathrm{C} 1$ $(p>0.05)$. The $F_{\text {max }}$ in group A3 was significantly higher than that in groups B1 and C1 ( $<<0.05)$, but it was not significantly different from that in group B2 or group $\mathrm{C} 2 \mathrm{p}$ $>0.05)$. The $\mathrm{F}_{\max }$ in group $\mathrm{B} 1$ was significantly lower than that in group $\mathrm{C} 3(\mathrm{p}<0.05)$, but it was not significantly different from that in group $C 2(p>0.05)$. The $F_{\max }$ in group $\mathrm{B} 2$ was significantly higher than that in group $\mathrm{Cl}(\mathrm{p}<$ 0.05 ) but not significantly different from that in group $\mathrm{C} 3$ $(p>0.05)$. The $F_{\max }$ in group B3 was significantly higher than that in groups $\mathrm{C} 1$ and $\mathrm{C} 2(\mathrm{p}<0.05)$.

The findings of Liu et al. showed that injection of 3.0 mL PMMA is most effective for increasing screw fixation when using the traditional augmentation method in severely osteoporotic lumbar vertebrae. ${ }^{19}$ Findings from our current study show that injection of $3.0 \mathrm{~mL}$ PMMA through screws with 4 holes in group A and injection of $2.5 \mathrm{~mL}$ PMMA through screws with 6 holes in group B can enhance screw stability to the same extent as injection of 3.0 mL PMMA in the traditional augmentation method. Taking into consideration the finding that PMMA distribution was closer to the pedicle in group B, we suggest injecting $3.0 \mathrm{~mL}$ PMMA through screws with 4 holes (placed as described) to decrease PMMA leakage into the pedicle. We believe that optimal results should be obtained with injection of $3.0 \mathrm{~mL}$ PMMA through screws with 4 holes when treating lumbar vertebrae with severe osteoporosis.

Our study had several limitations. In our country, body donations are rare, especially among the elderly, owing to cultural beliefs, which resulted in our having a limited number of samples. It has been reported that screw fixation strength is determined mainly by axial and vertical fixation strength. ${ }^{18}$ Clinically, the high incidence of screw failure due to loosening has been associated with cyclic loading..$^{14}$ Assuming that enough specimens are available in the future, we hope to perform multifaceted biomechanical tests, such as cycling loading tests, turning-back torque tests, and couple-screw fatigue tests. Additional research should also focus on the relationship between screw fixation strength and the distribution and volume of PMMA in severely osteoporotic VBs.

\section{Conclusions}

Our findings show that PMMA can significantly improve the stability of different injectable pedicle screws in lumbar vertebrae with severe osteoporosis; screw stability is significantly correlated with PMMA distribution pattern and the volume of PMMA that is injected. The closer the PMMA is to the pedicle and the greater the volume of PMMA that is injected, the greater the screw stability is. Nevertheless, at some point, changing distribution and increasing PMMA volume do not significantly augment the screw fixation strength but rather increase the risk of PMMA leakage. Injection of $3.0 \mathrm{~mL}$ PMMA through injectable screws with 4 holes should produce optimal stability in severely osteoporotic lumbar vertebrae.

\section{Acknowledgments}

This work was supported by the Health and Family Planning Commission Foundation of Sichuan Province (grant 16PJ020), the Science and Technology Plan Project of Sichuan Province (2017SZ0116), the National Natural Science Foundation of China (grant 81301606), and the Foundation of Chengdu Military General Hospital (grant 41732533).

\section{References}

1. Becker S, Chavanne A, Spitaler R, Kropik K, Aigner N, Ogon M, et al: Assessment of different screw augmentation techniques and screw designs in osteoporotic spines. Eur Spine J 17:1462-1469, 2008

2. Blattert TR, Glasmacher S, Riesner HJ, Josten C: Revision characteristics of cement-augmented, cannulated-fenestrated pedicle screws in the osteoporotic vertebral body: a biomechanical in vitro investigation. Technical note. J Neurosurg Spine 11:23-27, 2009

3. Bullmann V, Schmoelz W, Richter M, Grathwohl C, Schulte TL: Revision of cannulated and perforated cement-augmented pedicle screws: a biomechanical study in human cadavers. Spine (Phila Pa 1976) 35:E932-E939, 2010

4. Chang MC, Liu CL, Chen TH: Polymethylmethacrylate augmentation of pedicle screw for osteoporotic spinal surgery: a novel technique. Spine (Phila Pa 1976) 33:E317-E324, 2008

5. Chao KH, Lai YS, Chen WC, Chang CM, McClean CJ, Fan CY, et al: Biomechanical analysis of different types of pedicle screw augmentation: a cadaveric and synthetic bone sample study of instrumented vertebral specimens. Med Eng Phys 35:1506-1512, 2013

6. Chen LH, Tai CL, Lai PL, Lee DM, Tsai TT, Fu TS, et al: Pullout strength for cannulated pedicle screws with bone cement augmentation in severely osteoporotic bone: influences of radial hole and pilot hole tapping. Clin Biomech (Bristol, Avon) 24:613-618, 2009

7. Chen YL, Chen WC, Chou CW, Chen JW, Chang CM, Lai YS, et al: Biomechanical study of expandable pedicle screw fixation in severe osteoporotic bone comparing with conventional and cement-augmented pedicle screws. Med Eng Phys 36:1416-1420, 2014

8. Choma TJ, Pfeiffer FM, Swope RW, Hirner JP: Pedicle screw design and cement augmentation in osteoporotic vertebrae: effects of fenestrations and cement viscosity on fixation and extraction. Spine (Phila Pa 1976) 37:E1628-E1632, 2012

9. Cook SD, Salkeld SL, Stanley T, Faciane A, Miller SD: Biomechanical study of pedicle screw fixation in severely osteoporotic bone. Spine (Phila Pa 1976) J 4:402-408, 2004

10. Di Silvestre M, Parisini P, Lolli F, Bakaloudis G: Complications of thoracic pedicle screws in scoliosis treatment. Spine (Phila Pa 1976) 32:1655-1661, 2007

11. Fölsch C, Goost H, Figiel J, Paletta JR, Schultz W, Lakemeier $\mathrm{S}$ : Correlation of pull-out strength of cement-augmented pedicle screws with CT-volumetric measurement of cement. Biomed Tech (Berl) 57:473-480, 2012

12. Frankel BM, D'Agostino S, Wang C: A biomechanical cadaveric analysis of polymethylmethacrylate-augmented pedicle screw fixation. J Neurosurg Spine 7:47-53, 2007

13. Fransen P: Increasing pedicle screw anchoring in the osteoporotic spine by cement injection through the implant. 
Technical note and report of three cases. J Neurosurg Spine 7:366-369, 2007

14. Goel VK, Ebraheim NA, Biyani A, Rengachary S, Faizan A: Role of mechanical factors in the evaluation of pedicle screw type spinal fixation devices. Neurol India 53:399-407, 2005

15. Heo DH, Cho YJ, Cho SM, Choi HC, Kang SH: Adjacent segment degeneration after lumbar dynamic stabilization using pedicle screws and a nitinol spring rod system with 2-year minimum follow-up. J Spinal Disord Tech 25:409414,2012

16. Jindal N, Sankhala SS, Bachhal V: The role of fusion in the management of burst fractures of the thoracolumbar spine treated by short segment pedicle screw fixation: a prospective randomised trial. J Bone Joint Surg Br 94:1101-1106, 2012

17. Kaymaz B, Demirkiran G, Ayvaz M, Akel I, Acaroğlu E, Alanay A: [Treatment of thoracolumbar burst fractures using combined pedicle screw-laminar hook fixation.] Acta Orthop Traumatol Turc 48:152-156, 2014 (Turkish)

18. Kueny RA, Kolb JP, Lehmann W, Püschel K, Morlock MM, Huber G: Influence of the screw augmentation technique and a diameter increase on pedicle screw fixation in the osteoporotic spine: pullout versus fatigue testing. Eur Spine J 23:2196-2202, 2014

19. Liu D, Zhang B, Xie QY, Kang X, Zhou JJ, Wang CR, et al: Biomechanical comparison of pedicle screw augmented with different volumes of polymethylmethacrylate in osteoporotic and severely osteoporotic cadaveric lumbar vertebrae: an experimental study. Spine J 16:1124-1132, 2016

20. Liu D, Zhang XJ, Liao DF, Zhou JJ, Li ZQ, Zhang B, et al: Biomechanical comparison of pedicle screw augmented with different volumes of polymethylmethacrylate in osteoporotic and severely osteoporotic synthetic bone blocks in primary implantation: an experimental study. BioMed Res Int 2016:9627504, 2016

21. Moon BJ, Cho BY, Choi EY, Zhang HY: Polymethylmethacrylate-augmented screw fixation for stabilization of the osteoporotic spine: a three-year follow-up of 37 patients. J Korean Neurosurg Soc 46:305-311, 2009
22. Paré PE, Chappuis JL, Rampersaud R, Agarwala AO, Perra $\mathrm{JH}$, Erkan S, et al: Biomechanical evaluation of a novel fenestrated pedicle screw augmented with bone cement in osteoporotic spines. Spine (Phila Pa 1976) 36:E1210-E1214, 2011

23. Reitman CA, Nguyen L, Fogel GR: Biomechanical evaluation of relationship of screw pullout strength, insertional torque, and bone mineral density in the cervical spine. J Spinal Disord Tech 17:306-311, 2004

24. Waits C, Burton D, McIff T: Cement augmentation of pedicle screw fixation using novel cannulated cement insertion device. Spine (Phila Pa 1976) 34:E478-E483, 2009

25. Wang L, Li J, Wang H, Yang Q, Lv D, Zhang W, et al: Posterior short segment pedicle screw fixation and TLIF for the treatment of unstable thoracolumbar/lumbar fracture. BMC Musculoskelet Disord 15:40, 2014

\section{Disclosures}

The authors report no conflict of interest concerning the materials or methods used in this study or the findings specified in this paper.

\section{Author Contributions}

Conception and design: Zheng, Liu, Sheng, Wu. Acquisition of data: Zheng, Liu, Sheng, Wu, Xie. Analysis and interpretation of data: Liu, Sheng. Drafting the article: Liu, Kang. Critically revising the article: Zheng. Reviewed submitted version of manuscript: all authors. Approved the final version of the manuscript on behalf of all authors: Zheng. Statistical analysis: Wu, Kang, Luo. Administrative/technical/material support: Zheng, Kang, Xie, Luo, Zhou. Study supervision: Zheng.

\section{Correspondence}

Wei Zheng: Chengdu Military General Hospital, Sichuan Province, China. zyyzhengwei@126.com. 